\title{
CORPUS Corpus
}

Archivos virtuales de la alteridad americana

Vol. 7, No 2 | 2017

Julio / Diciembre 2017

\section{Sin un árbol que dé alegría. Experiencias del paisaje nativo y colonial en Mendoza entre los siglos XVI y XIX}

Without a tree to rejoice. Experiences of the native and colonial

landscape in Mendoza between the XVI and XIX centuries

Luis E. Mafferra and Bernarda Marconetto

\section{OpenEdition}

Electronic version

URL: http://journals.openedition.org/corpusarchivos/1939

DOI: 10.4000/corpusarchivos.1939

ISSN: 1853-8037

Publisher

Diego Escolar

\section{ELECTRONIC REFERENCE}

Luis E. Mafferra y Bernarda Marconetto, « Sin un árbol que dé alegría. Experiencias del paisaje nativo y colonial en Mendoza entre los siglos XVI y XIX », Corpus [En línea], Vol. 7, No 2 | 2017, Publicado el 11 enero 2018, consultado el 02 mayo 2019. URL : http://journals.openedition.org/corpusarchivos/1939; DOI : 10.4000/ corpusarchivos.1939

This text was automatically generated on 2 May 2019.

Licencia Creative Commons: Atribución-NoComercial 2.5 Argentina (CC BY-NC 2.5 AR) 


\section{Sin un árbol que dé alegría. Experiencias del paisaje nativo y colonial en Mendoza entre los siglos XVI y XIX ${ }^{1}$}

Without a tree to rejoice. Experiences of the native and colonial landscape in Mendoza between the XVI and XIX centuries

Luis E. Mafferra and Bernarda Marconetto

\section{EDITOR'S NOTE}

Fecha de recepción del original: 30/03/2017

Fecha de aceptación para publicación: 27/08/2017

\section{Introducción}

Es sabido que Mendoza era un desierto, pero no cualquier desierto. Era un páramo desolado, un lugar sin árboles y apenas con vegetación, como puede observarse en el óleo de 1936 de Rafael Cubillos sobre la fundación de Mendoza (Figura 1): una planicie seca y vacía, solo ceñida por los primeros cerros de la cordillera. Era un terreno hostil y dio lugar a una lucha encarnizada; pero no fue solo una lucha de hombres contra hombres sino que hubo también una guerra contra la naturaleza, la que tuvo que ser modificada radicalmente para permitir la supervivencia humana. Fue en esta gesta cuando se conformaron los actuales oasis, y si bien se acepta que sus cimientos más profundos se hundirían en tiempos prehispánicos, su concreción se asocia más bien al proceso colonial y a las migraciones europeas de finales del siglo XIX, acoplando la "construcción" de este paisaje a la acción domesticadora/civilizatoria de la conquista y al trabajo de los migrantes. 
2 Relatos como el repasado en el párrafo anterior caracterizan la relación entre sociedad ambiente en la provincia de Mendoza. Se trata de múltiples narrativas que configuran un sentido común, presente en variadas áreas de conocimiento y de la práctica. Su vigencia actual ha sido abordada a partir de diversos registros; se encuentra por ejemplo en la visión de los productores agrícolas "...el desierto no te regala nada", "no trabajaste un día” y "el desierto avanzó" (Montaña 2007, p. 287). Es común también en suplementos periodísticos "...para sobrevivir al desierto alimentamos con dificultad el oasis...con sus propias reglas de hierro. Todos debemos respetarlas, bajo pena de desaparición" (Diario Uno 2011 en Escolar et al. 2012, p. 77). Del mismo modo, este tipo de sentidos es corroborado en los discursos y prácticas que naturalizan el modo en que se articulan políticas públicas que otorgan o niegan el derecho de provisión de agua entre sectores intra o extra oasis (Saldi et al. 2014). Estas narrativas se mezclan incluso en la elaboración de conocimiento científico. En un minucioso trabajo sobre la historia de las leyes de Mendoza se dice al pasar: "la ciudad luchaba por sobrevivir en el descampado y agreste territorio donde se había situado" (Segheso 2007, p. 228), replicando casi exactamente el paisaje representado en el lienzo de Rafael Cubillos.

Con relación a los árboles, elementos en los que pondremos el acento en este trabajo, la imagen de este páramo desolado con el que se caracteriza al paisaje precolonial, da razón de ser al actual paisaje forestado. Es común escuchar cómo en Mendoza sin los árboles introducidos "sería imposible la vida" (Anónimo 2007); o cómo en la guerra contra la naturaleza antes señalada "El árbol (...) es un potente grito de rebeldía. Es alzarse con justificación contra el tirano, que aquí se llama Desierto" (Paz 2016).

4 Estas narrativas forman parte de un "ideario ambiental mendocino" y son caracterizadas como un tipo de discurso "de la provincialidad" o "colonial", es decir, un conjunto de mitos constituidos en perspectiva hegemónica para interpretar la realidad (Escolar et al. 2012). En éstos la historia se recuerda, olvida, reconstituye o deforma en pos de la legitimación de valores o intereses hegemónicos (Montaña 2007). De esta forma, se actualizan constantemente y se naturalizan constituyendo sentidos que justifican procesos sociales de jerarquización económica, social o cultural y especialmente territorial, donde ciertos espacios se asociaron al desierto y así a lo salvaje y la barbarie y el oasis se plegó a lo doméstico y a la civilización (Escolar et al. 2012; Saldi en prensa).

5 Si bien se propone que este ideario ambiental habría cristalizado en el siglo XIX, se asocia también a procesos políticos y a discursos que comenzaron con la conquista española (Ponte 2007; Escolar et al. 2012). En este sentido, iremos en este escrito tras los indicios coloniales de estas narrativas en la provincia de Mendoza. Analizaremos documentos de diversa naturaleza producidos por cronistas histórico-militares, ${ }^{2}$ cronistas pertenecientes a órdenes religiosas ya sean jesuitas ${ }^{3}$ o dominicos; ${ }^{4}$ de cartas o informes correspondientes a la orden Jesuita; ${ }^{5}$ así como relatos de viajeros ${ }^{6}$ o documentos correspondientes a procesos judiciales. ${ }^{7}$ Se trata de materiales que contienen descripciones históricogeográficas, escritas por autores que conocieron o tuvieron informes de nuestra región de estudio. La mayoría de ellos son ya conocidos por haber sido presentados e interpretados desde diferentes enfoques en otras contribuciones que discutiremos a lo largo del trabajo (por ej. Canals Frau 1946; Michielli 1983; Coria 1988; Prieto 1985, 1987, 1989, 2000, 2007; Prieto y Wuilloud 1986; Lacoste et al. 2011, entre otros). Indagaremos aquí las experiencias del ambiente entre los siglos XVI y XIX. Especialmente, nos interesan las valoraciones y sentidos presentes en este tipo de testimonios. Las observaremos en base a agrupamientos específicos de materialidades-significados o colectivos, delimitados en 
este caso como paisaje nativo, por un lado, y colonial, por el otro. Con el fin de facilitar al lector la comprensión de las perspectivas, integraremos los testimonios de estas valoraciones y sentidos en un discurso referenciado documentalmente que, por momentos, será articulado de forma narrativa. Nuestro objetivo será comprender las experiencias a la par de modalidades de relación con el ambiente, por lo que contemplaremos no solo la conformación de discursos, sino también la de corporalidades y paisajes. No pretendemos en este trabajo dar una explicación total, ni establecer causalidades rígidas, tampoco creemos haber agotado el acervo documental sobre el tema. Más bien compartiremos un itinerario de preguntas y reflexiones que fueron surgiendo en el camino interpretativo que presentaremos aquí. En este camino también discutiremos algunos aspectos metodológicos que consideramos prematuro abordar antes de empezar. Por esto, y porque queda mucho por andar, sin demorar más avancemos.

\section{Las tierras melancólicas}

6 Entre los vecinos del Santiago de Chile colonial no existía peor "mortificación" que saberse condenado a una vida en Cuyo (Ovalle 1646, p. 76). No vamos a negar aquí que había razones para considerarse perjudicado si esto llegaba a ocurrir. Para empezar, llegar a Mendoza implicaba el cruce de los Andes y entre los siglos XVI y XVIII esta aventura solo era posible en los meses estivales. Aún en verano cruzar "la gran cordillera nevada" exponía a los viajeros a condiciones extremas. Había que resistir "grandes tempestades", "violentísimos" temporales de nieve y "bravos" vientos. Sin embargo, en este peregrinar donde los fríos partían labios y mejillas, las bajas temperaturas no representaban el principal peligro sino el aire, que era "tan sutil" que no podía ser respirado por los seres humanos (Herrera 1615, p. 487). No solo eso, la ruta acercaba a los viajeros a catorce grandes volcanes que ardían constantemente (Anónimo 1776 en Prieto 2000, p. 39). El panorama en esta parte del trayecto era desolador, la vegetación estaba totalmente ausente: no existían ni pastos, ni montes. Para colmo de males, esta lúgubre aventura solo podía completarse si se evitaba el constante peligro de perder la orientación, ya que los continuos terremotos borraban y cegaban "de infinita piedra" los senderos (González Nájera 1889 [1601], p. 14).

7 En la parte más alta de la cordillera, los malos presagios que se rumoreaban en Santiago se materializaban en el tenebroso panorama que vestía el cielo del oriente. Desde allí, Cuyo se veía cubierto de "gruesos vapores" que dejaban a aquella parte entre las sombras mientras, al occidente, el cielo de Chile era tan "cristalino y dorado" que causaba "alegría verlo" (Ovalle 1646, p. 29). Esa dicha pronto se desvanecía ya que el descenso adentraba a los expedicionarios en una tierra "melancólica" con pocos ríos y, los pocos, turbios. Todo el trayecto no mostraba un árbol "que dé alegría". Con la llegada a los valles cordilleranos los viajeros olvidaban rápidamente el frío, ya que comenzaba a ser tanto el calor que todo se teñía de "tristeza y desgano" (Ovalle 1646, p. 29).

8 Alcanzar el piedemonte no daba descanso a los viajeros. Sus tierras "guadalosas, salitrosas, quebradas y pedregosas", solo servían para pasturas en años de abundante agua, las demás eran todas "áridas e infructuosas" (Prieto y Wuilloud 1986, p. 11-sic-). Parecían tierras sobradas donde sólo existían "espinas" (Ovalle 1646, p. 29).

El sosiego tampoco se hallaba en las llanuras ya que era toda tierra "asperísima": "tan estéril e incómoda y tan peligrosa y de moradores pobrísimos" siendo mucho, por lo mismo, el peligro de "enfermar y morir" (Anónimo en Canals Frau 1945, pp. 88 y 92 -sic-). 
Más precisamente, la planicie al noreste era "miserabilísima" (Cartas Anuas 1927 en Prieto, 2000, p. 46); los territorios puelches al sur eran aún peores, tierras tan agrias y frías como inhabitables (Bibar, 1952, p. 137).

10 Al igual que en la cordillera, en las planicies y piedemontes el clima se manifestaba de forma terrible. En verano las temperaturas eran insoportablemente elevadas y en invierno las heladas congelaban el agua bajo el techo de las casas. Mientras que en todo el invierno no llovía una gota, durante el verano las tormentas eran tales que derribaban casas y hasta iglesias. Por su parte, los truenos y rayos sembraban el terror por lo que las nubes debían exorcizarse blandiendo las campanas de las iglesias. Estas tormentas también deparaban granizadas de piedras del tamaño de "huevos de gallina, pato y aún de avestruz" (Ovalle 1646, pp. 2-3).

11 A estas calamidades ambientales se sumaba la de los árboles de Cuyo. Si bien las planicies estaban bien pobladas de "espinos", éstos se revelan como árboles "más ofensivos que provechosos". Sus frutos eran, para algunos, “desabridos" (González Najera 1889[1601], p. 15) o, para otros, tan dulces "que empalagan" (Ovalle 1646, p. 74). Eran, parece, difíciles de comer para los españoles. Por su parte, su madera podía aprovecharse poco, ya que, aunque era "muy dura" era otro tanto "vidriosa" (Gómez de Vidaurre 1776 en Prieto 2000, p. 43). Tal vez por esto no servía para la maderación de las casas (Lizárraga s.f. en Canals Frau 1946, p. 24). Si bien en estos llanos se dice que abundaban los espinos, en el trayecto que unía Mendoza con Guanacache se denuncia la inexistencia de "un árbol o cosa donde poderse reparar", lo que exponía a los viajeros al peligro de morir por el calor y la sed (Cartas Anuas 1927 en Prieto 2000, p. 46).

12 Los animales de estas regiones no eran tan malos, había numerosos guanacos, ciervos y peces de gran calidad (Olivares 1778 en Prieto 2000, p. 45; Ovalle, 1646, p. 5). Sin embargo, se advierte sobre los peligros debidos a la gran cantidad de chinches, mosquitos y serpientes; además de las plagas de langostas que cubrían el cielo y comían hasta la corteza de los árboles (Olivares 1736 en Prieto 2000, p. 40).

\section{Las corporalidades y las cordilleras}

13 Los testimonios revisados bastan para lograr una idea de cómo experimentaban los colonos y viajeros los paisajes nativos de Mendoza, entre los siglos XVI y XIX. Puntualmente, estos documentos han sido utilizados para la reconstrucción paleoambiental de la zona, desde un enfoque ecológico cultural (Prieto 1985, 1989, 2000; Prieto y Wuilloud 1986). En ese caso, el carácter de este tipo de percepciones es parte de un "filtro" que debe ser atenuado para comprender los hechos objetivos registrados más allá de las experiencias de los actores. Por ejemplo, M. R. Prieto (2000, pp. 38-39) advierte cómo la tendencia a la exageración -intencionada o no-, o las fabulaciones presentes en este tipo de documentos pueden hacer referencia a fenómenos inexistentes. En el mismo sentido, también puede argumentarse, en algunos casos con razón, que estos discursos eran parte de una táctica que buscaba obtener beneficios políticos por medio de la exageración de las experiencias penosas tenidas en relación a los territorios colonizados (Prieto 2007, p. 616). Sin embargo, aquí nos interesa otro aspecto, uno que L. Boia (2004, p. 16) señaló con precisión en relación con documentos de similar naturaleza. Este autor analiza versos del poeta romano Ovidio, en los que refiere de forma pavorosa al clima de Tomis, antigua colonia griega en la actual Rumania, donde se encontraba exiliado. Boia señala que, si bien las exageraciones del poeta pueden entenderse dentro de las licencias 
de su oficio o como una táctica para inspirar la piedad de los romanos, las mismas son esencialmente "la expresión poética de un esquema organizador del mundo".

En el mismo sentido, nosotros entendemos que las percepciones y los fenómenos narrados conforman una unidad que, a través de un ejercicio de desciframiento, puede delatar la perspectiva que modelaba las experiencias de los actores. En nuestro caso propusimos observar de forma comparativa los sentidos en relación con el ambiente, nos detuvimos en las valoraciones vinculadas a entidades y fenómenos, y en las narrativas en torno a las experiencias. Entendemos que estas pueden resultar indicios que permiten observar diferentes disposiciones de relación con el ambiente.

Vimos, por ejemplo, lo penoso que resultaba el cruce de los Andes para colonos y viajeros europeos. Si bien estas montañas se revelaban como una primera barrera ambiental para dichos actores (Prieto 2000), esta situación no parecía darse en otros contextos. Por ejemplo, la cordillera no habría representado un condicionante o un límite para los indígenas huarpes durante ese mismo período. En este sentido, los cronistas dejan testimonio de su asombro al ver a los naturales cruzar cordillera "casi desnudos", aunque las montañas estuvieran gran parte del año cargadas de nieve (Michieli 1983, p. 89). También, señalan cómo podían escalar los "asperísimos montes" con la ligereza de los "gamos". ${ }^{8}$ Esta destreza era incluso demostrada por niños o mujeres, aun cuando estas últimas cargaban a sus hijos en sus espaldas colgando de sus cabezas (Ovalle 1646, p. 110). Se observa también cómo podían cruzar la montaña durante el invierno, cuando para los colonos se revelaba vedada. Por esto se les encargaba ser mensajeros entre las ciudades de ambas vertientes de los Andes (Michieli 1983, p. 111); o les servía para escapar de las encomiendas en Santiago y regresar a Mendoza sabiendo que sus encomenderos no se atreverían a seguirlos durante esa temporada (Michieli 1983, p. 87). En el mismo sentido, podemos entender cómo en tiempos recientes las montañas no constituyen un límite para los puesteros de las zonas cordilleranas, sino un espacio de encuentro e integración entre pastores de ambos lados de los Andes (Escolar 2007, pp. 113-114). No obstante, para los conquistadores europeos la cordillera constituyó una barrera difícil de afrontar, sobre todo hasta finales del siglo XVIII (Prieto 1987, p. 18).

Esto delata diferentes perspectivas frente a similares materialidades ¿Cómo entendemos estas diferentes experiencias? Es posible observarlas modeladas por la conformación relacional de corporalidades en las que se incorporan formas particulares de experiencia. En estos términos, la percepción se describe como una cualidad inducida a partir de un proceso de aprendizaje (Ingold 2000, p. 22). Es decir, en el codesarrollo de personas y ambiente se produce un ajuste entre las materialidades y los sentidos. En estos términos, podemos entender que el ambiente cordillerano y las corporalidades nativas formaban parte de un mismo proceso conformativo, mientras que otros cuerpos eran ajenos a este proceso.

17 Ciertamente, además, en estos movimientos se conjugaban y confundían materialidades y significados, categorías que en la práctica terminan por disolverse. ¿Pero cómo se incluyeron los significados en este proceso? Nuevamente, resulta ilustrativo observar un ejemplo, donde puede verse cómo los colonos no valoraban a todos los lugares del Nuevo Mundo como igualmente desgraciados. ${ }^{9}$ 


\section{Comparaciones odiosas}

18 Para dejar en claro el desencanto causado por Mendoza, algunos cronistas la cotejaron con Chile. En este sentido, incluso desde el cruce de los Andes encontramos cómo el cielo sobre Cuyo ya deparaba un panorama aterrador. En contraste el cielo de Chile era tan armonioso que bastaba verlo para alegrarse. En oposición a lo terrible de la experiencia de los paisajes nativos de Cuyo, las crónicas que refieren a los paisajes de Chile central son en cambio muy positivas. Los cielos y los suelos de Chile se ostentan como los mejores que se hayan visto. Se elogia su clima y sus plantas se describen con ensalzada belleza (Ovalle 1646, pp. 2-5). Los colonos y viajeros proponían explicaciones de esta notable diferencia. Más precisamente, la culpable era la cordillera ya que, así como divide el cielo y el clima, también dividía la tierra haciendo "diferenciar los árboles, hierbas, plantas y animales que hay en ella" (Ovalle 1646, p. 29). Otro cronista afirma que también las montañas servían para "atajar" los vientos, los fríos y las tempestades de truenos y rayos que azotaban Cuyo, pero que a Chile no llegaban (Mariño de Lobera 1584 en Prieto 2000, p. 40). Más allá de las razones, entre ambos lugares se reconocía "tan notable variedad y diferencia" que valdría para afirmar que "la naturaleza en la fábrica y disposición de esta parte del mundo" le habría dado la cara a las tierras de Chile, mientras le habría vuelto las espaldas a las de Cuyo, llenando a unas de bendiciones y dejando "llorar de envidia" a las otras, como a "un hijo segundo" (Ovalle 1646, p. 29). Como hijos segundos, los autores sabemos de qué habla el cronista; pero ¿qué sentidos subyacían en estas experiencias?

Algunos autores han planteado que este tipo de percepciones sobre el Nuevo Mundo estaban profundamente arraigadas en el pensamiento occidental y deben analizarse en el contexto de la tradición judeo-cristiana. Se propone que el ambiente era percibido dentro de una dicotomía en la que podía adoptar la forma de la "selvatiquez" o el "paraíso" (Nash 2014). Se trataba de representaciones cuyas raíces pueden hallarse en los tiempos bíblicos de los profetas. De este modo, o bien el ambiente podía adoptar la forma del edén hallado en los textos sagrados -es decir, un jardín paradisíaco asimilable a los presentes en la tradición pérsica e islámica en donde humanos y naturaleza se encontraban en una armonía que no los enfrentaba ni distinguía-; o, por el contrario, podía adoptar la forma de la selvatiquez, espacio que incluyó elementos de las mitologías de la Europa pagana e invocaba lo salvaje, lo incontrolable lo oscuro y temible en los humanos y en la naturaleza. Era habitada por personajes amenazadores y podía representarse como desiertos pedregosos abrasados por el sol, o como oscuros bosques de soledades "aullantes" de árboles, marismas y seres sobrenaturales. Para los nuevos habitantes o visitantes ocasionales, en estos espacios existía además el peligro de perder el sostén de la civilización y corromper física y moralmente la naturaleza cultural humana, en otras palabras, volverse salvaje (Nash 2014, pp. 8-9). Esto es evidente cuando se describen las razones negativas para el establecimiento de doctrinas en la región de Cuyo explicando cómo entre los "peligros" para mantener "en pie la disciplina religiosa" estaban los "calores excesivos que distraen mucho" (Canals Frau 1945, p. 90). Del mismo modo, es notable en ciertas características bestiales reconocidas en los indígenas. Más arriba subrayamos cómo subían los asperísimos montes "como gamos", lo que parece corresponder a una relación recurrente en donde los habitantes de climas extremos, tenían comportamientos extremos y a mitad de camino entre el de los humanos y las bestias (Boia 2004). 

Chile y Cuyo, podría resultar la expresión de estos sentidos. Se trataba de proyecciones sobre las formas en las que el ambiente podía revelarse y formaban parte de la perspectiva a partir de la cual colonos y viajeros europeos establecían su relación con las materialidades del Nuevo Mundo. No entendemos aquí que se tratara de ideas que mediaran las relaciones entre las corporalidades y el ambiente, sino de sentidos incorporados que configuraron de forma espontánea las relaciones con la materialidad. Sugerimos que estas disposiciones se incorporaban contextualizadas en colectivos o asociaciones específicas de materialidades-significados, que adoptaban la forma de lugares característicos o paisajes. En éstos, el ambiente expresaba una forma familiar, era parte de un modo de habitar donde los actores se encontraban implicados o integrados. En este sentido, se ha propuesto que las valoraciones contrapuestas entre Chile y Cuyo, revisadas más arriba, se deben a que la región chilena fue señalada por algunos cronistas como climáticamente asimilable con Europa (Prieto 2000, pp. 40-41). Si bien vimos que existen estas analogías también se mencionan diferencias que hacían a Chile incluso mejor que Europa. Por ejemplo, su clima era aún más benigno por tener tanto fríos como calores menos rigurosos que los del Viejo Mundo, y estaban libres de rayos, truenos, tempestades y granizo. Además del clima, la información revisada permite corroborar que las características especiales reconocidas también involucraban a la tierra, árboles, hierbas y animales. Así, no había en este reino víboras, chinches o tipo alguno de animal ponzoñoso, lo que permitía "revolcarse entre la hierba sin temor". Las aguas eran delicadas, cordiales y saludables, la comida era más sustanciosa por lo que bastaba con comer menos. Los montes de espinos, parecían encinos u otros como los robles, daban tanta leña que a pesar de haber servido muchos años a la vida humana seguían "tan enteros y espesos que penetrando un poco adentro no se podían romper". Se menciona un aspecto interesante, y es que, a raíz de que era tanta la "fuerza con que la tierra arroja y produce" en muchas partes, no se distinguían los campos incultos de los sembrados. De este modo, muchas plantas domésticas podían crecen en Chile sin ninguna ayuda o beneficio humano (Ovalle 1646, p. 2-5).

Existían así un conjunto de elementos que posiblemente rememoraba los ambientes que eran familiares a los colonos, pero más que con climas o entornos físicos, estas analogías se realizaban en términos de paisaje, es decir: configuraciones de materialidadessignificados enredadas con prácticas que permitían re-actualizar las experiencias. Así, en Chile se concretaba la proyección paradisíaca del ambiente, y ésta se caracterizaba por un entorno donde el tipo de vida pretendido por los colonos podía desarrollarse fácilmente. La naturaleza parecía predispuesta a un tipo de socialización cercana a la europea donde no se distinguían los espacios sostenidos por el trabajo humano de los que no.

Por otro lado, se plantea que las experiencias de los paisajes nativos debieron ser diferentes en base al lugar de procedencia de los diferentes colonos (Prieto 2000, p. 38). Si bien se trata de una pregunta pertinente, no podemos -ni pretendemos- afrontarla aquí con la precisión que requiere pero consideramos útil comenzar planteándola a nivel general y en clave de las ideas que estamos discutiendo. Entonces, ¿cuáles eran los paisajes que dominaron la península ibérica entre los siglos XVI a XIX? y ¿cuáles los paisajes nativos del norte de Mendoza que tan extraños resultaban a las sensibilidades de los colonos? 


\section{Los paisajes, las experiencias y los árboles}

Hemos observado las experiencias del ambiente en el período colonial. Precisaremos ahora cómo era el carácter de las mismas; y propondremos que los árboles tuvieron un lugar especial. Retomaremos primero los interrogantes con los que finalizamos el apartado anterior.

25 En relación al primero, la Europa de la última parte de la Edad Media y el Renacimiento se veía inclinada hacia el idilio pastoril de un paisaje cultivado, luminoso y ordenado. Por su parte, los reinos de la península ibérica de los siglos XV a XVIII seguían atados a una economía principalmente pastoril que fue la que se transfirió a América en el proceso de conquista (Arnold 2000, p. 122). Por otro lado, la larga estancia de los moros en los actuales territorios españoles les habría legado a los reinos cristianos su gran conocimiento y manejo silvícola, práctica que, aunque hacia el final de la Edad Media era rara en Europa, habría logrado gran difusión en la península ibérica incluso entre los estratos populares (García Sánchez 2015). Este paisaje incluía también montes o bosques, que tenían en este contexto una gran importancia social y económica (Vigil 2003). Estos espacios no deben a priori considerarse salvajes, ya que en dicho contexto no se habitaban en base a relaciones diferenciadas de los espacios domésticos. Por ejemplo, los árboles silvestres de los que se obtenía leña debían cuidarse y cultivarse como los del huerto (Mafferra 2016a); y, si bien la caza en las monterías implicaba el riesgo cierto de volverse "salvaje" (Hell 2000), debía procurar una economía de acciones que incluía el manejo de temporalidades y espacialidades que escapan a nuestra idea moderna de lo "salvaje". Se trataba de ambientes profusamente socializados que integraban ámbitos comprendidos por nosotros como salvajes o domésticos. Así, el paisaje del Viejo Mundo durante ese período se delineaba por sus prácticas como agrícola, pastoril, silvícola y montaraz. Se trataba de paisajes salpicados de sementeras, grandes rebaños de ovejas y manadas de bóvidos, huertos de árboles frutales, así como sectores de montes o bosques.

Por su parte, los ambientes de los piedemontes y planicies del norte de Mendoza se caracterizaban por grandes extensiones de montes nativos. La composición de esos montes puede delinearse en base a datos arqueológicos (Mafferra 2015, 2017), documentales (Prieto 1985, 1989, 2000; Prieto y Wuilloud 1986) y a estudios de la vegetación actual (Ambrosetti 1972, Méndez 1999, Perosa et al. 2013, Roig 1972, Roig et al. 2000). Puntualmente se relaciona al paisaje forestal nativo con el característico de la provincia fitogeográfica del Monte. En líneas generales estaría conformado por el jarillal ( Larrea sp.), acompañado por plantas dispersas de forma arbórea de chañar (Geoffroea decorticans), algarrobo (Prosopis sp.) y retamo (Bulnesia retama). Además, los datos señalan que los cauces que surcaban los piedemontes eran franqueados por bosques en galería de Acacia y se estima que formaciones de algarrobales y retamales cubrieron grandes extensiones de las planicies que hoy se encuentran deforestadas (Abraham y Prieto 1999, Perosa et al. 2013, Prieto et al. 2003, Roig 1972, Rojas 2009, Rojas et al. 2009). Estos montes se alternaban con amplios espacios lacustres, donde se practicaba la pesca, la caza y se obtenían vegetales (Prieto y Chiavazza 2006). Hay evidencia ambigua y discusiones abiertas sobre cauces y sectores lacustres o periódicamente inundables donde los grupos nativos practicaban la agricultura (Mafferra 2010, Mafferra 2016b). Entonces, en el caso nativo, el paisaje se delineaba por las prácticas cinegéticas, la pesca y la recolección de frutos y, posiblemente, el cultivo. Este modo de habitar es corroborado en múltiples 
trabajos arqueológicos e históricos (Canals Frau 1946; Michielli 1983; Prieto 2000; Durán y García 1989; Chiavazza y Mafferra 2007; Gil et al. 2009; Chiavazza 2010, 2015).

Del mismo modo que con la cordillera, las sensibilidades nativas seguramente estaban ajustadas con las materialidades de ese paisaje. Existen muchas menciones donde se describe cómo los indígenas habitaban casi sin construir casas donde vivir, bastándole solo unos reparos de ramas (Canals Frau 1945, p. 88; Ovalle 1646, pp. 101-102, Techo 1897 en Michieli 1983, p. 191). En el mismo sentido se dice que los pampas, sus vecinos del este, tenían tan olvidado el miedo a los "rigores e inclemencias del tiempo" que vivían sin buscar más casa que "la tierra", ni más techo "que la bóveda del cielo estrellado" (Ovalle 1646, p. 103-104). Lo efímero de sus refugios o su inexistencia delatan que los montes eran propiamente su morada.

Vemos que los datos empíricos no avalan la existencia de un páramo desolado como el descripto en los mitos o discursos de la provincialidad revisados en el primer apartado. Sin embargo, ¿qué sucede cuando corporalidades asociadas a otras materialidades experimentan este ambiente? Si bien el paisaje actual representa solo un despojo de lo que debió ser en el pasado, ¿qué nos ocurre cuando a razón de nuestro trabajo de campo debemos adentrarnos en el monte? Se trata de una situación a priori mediada por la incomodidad o la extrañeza; en algunos casos puede hasta ser aprensiva. Generalmente, para poder sostener la experiencia procuramos proteger nuestros cuerpos con un disfraz de exploradores. Aunque las botas de montaña dudosamente contribuyan a transitar los médanos, junto con los sombreros de tela, los pañuelos en el cuello y las camisas de tonos soldadescos, sirven para poner distancia con una materialidad que se nos revela hostil. ${ }^{10}$ Ciertamente, no buscamos hacer una analogía entre nuestra experiencia y la de los colonos en el pasado. Más bien creemos que ésta poco tiene que ver con nuestra experiencia moderna, especialmente si es mediada por inquietudes científicas donde fenómenos discretos pretenden percibirse, medirse y analizarse de forma aislada (el clima, la vegetación, el relieve, etc.). Sólo deseamos remarcar que hasta en nuestro caso nos vemos enajenados por una materialidad que nos desborda.

Más claramente, para comprender cómo el ambiente se experimentaba, especialmente en el contexto de estudio al que nos estamos refiriendo, resulta útil la idea de "inhabitar" propuesta por T. Ingold (2011). Según esta definición el ambiente se vivencia, antes de observarse o medirse, y la percepción, dispuesta como dijimos por experiencias conformativas previas, implica un movimiento de inmersión en la dinámica del mundo que integra el suelo, el cielo, el aire y la vegetación. En este sentido, durante los siglos XV al XVIII, el ambiente se presentaba de forma caleidoscópica; si bien algunos autores hacían hincapié en uno u otro fenómeno, el temple o el carácter de un lugar y su gente se delineaba por la sutil interacción del relieve, la vegetación, las mareas, las comidas o el aire (Boia 2004). Vimos cómo las bondades de las tierras y el cielo de Chile estaban dadas por las montañas que frenaban las tormentas y que, junto con las mareas, templaban fríos y calores; por lo sustancioso de su comida; por la calidad de su aire (que incluso mataba las chinches que eran plaga en Mendoza); por lo regalado de sus montes o las suaves lluvias que lavaban el cielo y vestían de verde los prados que florecían cargados de hermosura (Ovalle 1646, p. 2-6).

En este trabajo queremos subrayar cómo en esta experiencia total los árboles tuvieron un lugar especial en relación al proceso que estamos describiendo. Se plantea que los árboles forman parte activamente de la construcción de los lugares y tienen la capacidad de crear respuestas afectivas (Jones y Cloke 2008, p. 80). En este sentido, la ausencia de "un árbol 
que dé alegría" fue la forma de expresar el desasosiego con el que transitaban los paisajes cordilleranos. Los árboles intervienen en la experiencia total del entorno, especialmente en la del clima (Mafferra 2015, p. 45). De este modo, las personas en su vida cotidiana quedan entramadas en un tipo particular de paisaje forestal, lo que propicia un ajuste entre las materialidades de estos paisajes y los sentidos (que en relación a los árboles son visuales, olfativos o sonoros, entre otros).

Con respecto a las experiencias de los árboles nativos de Cuyo, en algunos testimonios se reconoce que las planicies estaban pobladas de "espinos", los que se han asociado a los bosques de algarrobos pero que quizás incluían otros elementos del bosque nativo. Prieto (2000, p. 41) señaló cómo éstos no eran considerados recursos al no ser culturalmente reconocidos durante el período colonial, especialmente en relación con la denuncia de la falta de leña para la maderación de las casas (Lizárraga s.f. en Canals Frau 1946, p. 24). Observamos también que ni su madera ni sus frutos eran valorados; y no solo no eran considerados provechosos, sino que eran "ofensivos". Del mismo modo, a pesar de que existieran muchos espinos en las planicies, decían también que al transitarlas "no había un árbol o cosa donde poderse reparar". En base a esto mismo, podemos cuestionar si éstos eran considerados por algunos actores auténticamente "árboles", al menos en relación con el clima, al no ofrecer reparo para el calor y la insolación.

Así como los árboles nativos contribuían en la experiencia negativa del ambiente, veremos cómo la situación se revierte cuando en las experiencias intervienen las plantas introducidas.

\section{Las tierras ennoblecidas}

33 En contraste a las experiencias negativas en torno al paisaje nativo de Cuyo descriptas más arriba, cuando los testimonios refieren a la conformación del paisaje propiamente colonial las valoraciones se invierten y las "exageraciones" son positivas. Esto se observa especialmente cuando refirieren a las posibilidades concretadas de la conformación de un nuevo paisaje, claramente más familiar a la vida de los colonos. Las mismas zonas antes valoradas como pobres o ambientalmente desgraciadas, se describen como verdaderos vergeles donde "se dan todas las frutas, árboles y viñas" y, donde había poca comida y regalo, ahora son tierras "ennoblecidas" por las muchas cabras que la pueblan (Proceso a Villagra en Prieto y Wuilloud 1986, p. 23).

En consonancia con estos testimonios existen evidencias arqueológicas, principalmente restos de madera y de semillas carbonizadas, recuperados en contextos coloniales del sitio ciudad de Mendoza (siglos XVI a XVIII), que permiten proponer que, en paralelo a un proceso de desestructuración del monte nativo en torno a la ciudad colonial, se habría dado el ingreso de varias especies de árboles europeos: Frutales como el duraznero ( Prunus aff. persica), una pomácea no determinada posiblemente membrillero, manzano o peral (Aff. Cidonia/Malus/Pirus), vid (Vitis sp.) y olivo (Olea sp.); como también, un árbol con funciones menos explícitas a nuestro sentido como el tamarindo (Tamarix aff. gallica), cuya implantación estuvo tal vez asociada a su valor ornamental, medicinal o simbólico (Mafferra 2011, 2015, 2017, Mafferra et al. 2015). Además del ingreso de estos árboles, los datos arqueológicos avalan el desarrollo de otros cultivos de origen europeo. Sementeras de cereales como el trigo, la avena o el centeno y campos de alfalfa destinados a pasturas habrían comenzado a ser característicos en este nuevo paisaje (Mafferra 2011, 2016b). Ante lo dicho, las referencias que veremos en este apartado se dieron, más allá de las 
exageraciones, a la par de la conformación material de un paisaje nuevo, caracterizado por una impronta agrícola-pastoril.

Así, los testimonios escritos refieren especialmente a la variedad, cantidad y calidad tanto de los árboles introducidos como de sus frutas. Aun reconociendo que el ambiente mendocino era muy inferior al chileno, se dice que "las cosechas de Cuyo son más abundantes y las frutas mayores y más sazonadas que en Chile" y se aclara que "...es esta tierra abundantísima de pan, carne, vino, legumbres y todo género de frutas de Europa", especialmente "almendros y olivos" (Ovalle 1646, p. 57). Otras fuentes, se detienen para dejar claro que en Mendoza:

“...se hallan todas las especies de frutales que conoce en toda su extensión la Europa y América. Si acaso se echa de menos en ella alguna de ellas, esto podrá ser porque ha faltado la mano bienhechora que se aplique a cultivarla..." (Carta $3^{\mathrm{a}}$, Fuente americana, en Coria 1988, p. 176).

Se afirma que existen varias especies de duraznos, peras y manzanas, "todas de un gusto y sazón perfecto". Continúa sorprendiendo la cantidad y la calidad. Las peras "se ven en abundancia", las manzanas "se hallan muchas de un sabor y gusto exquisito", “...la ciruela, la guinda, el albaricoque, vienen en Cuyo con excelente perfección". Se aclara con sorpresa cómo "es increíble cuánta fruta llega a dar cada árbol de las especies dichas y singularmente de las dos últimas" (Carta 33 , Fuente americana, en Coria 1988, p. 176).

Se deja testimonio de las fincas de Mendoza que producen "infinito vino" así como de los potreros de alfalfares y prados "artificiales" cercados con paredes (Eusebio Videla s.f. en Coria 1988, p. 81). La exuberancia antes tenebrosa, ahora aparece asociada al asombroso crecimiento de las plantas introducidas. Se detalla cómo crecen las higueras en las vertientes orientales del reino de Chile, que se dan mayores que en Europa o todas las partes de las indias. Particularmente, se explican cómo aquí estos árboles engrosan tanto su tronco que son necesarios "dos, o tres o cuatro hombres para abrazarle" (Ovalle 1646, p. 56). En la misma sintonía, en el siglo XVIII se habla de Olivos cuyo "desmedido tronco" se relaciona con la "ancianidad de su existencia" y con la historia de los primeros pobladores españoles, los que lograron reconocer las condiciones especiales para su cultivo (Castro 2015, p. 95).

Las menciones sobre la existencia de árboles introducidos se generalizan en el siglo XIX, destacando el duraznero, seguido por el damasco, peral, naranjo, higuera, nogal, entre otros (Lacoste et al. 2011). En las fuentes siguen apareciendo testimonios que dan cuenta del crecimiento en Mendoza de olivos y árboles frutales de todo tipo (Mellet 1959 [1824], p. 66). Hasta Charles Darwin, en la tercera década del siglo XIX, ironizó a su paso por Mendoza, sobre el prominente desarrollo de los frutales europeos, creciendo en un paraje y clima tan inhóspitos donde, en su opinión, la gente no podía más que comer, dormir y estar ociosa (Darwin 2003, p. 396).

En cuanto al ámbito urbano, hasta el siglo XVIII, los árboles se habrían desarrollado fundamentalmente en las quintas al interior de los solares, en base a que las hijuelas de acequia atravesaban los terrenos, permitiendo su riego (Ponte 2006, 2015). Si bien no conocemos análisis profundos sobre cuándo habría comenzado a ser común el arbolado público, se estima que a partir del siglo XVIII, las acequias comienzan a ubicarse en las calles (primero al centro luego en los bordes), permitiendo el desarrollo de la forestación en dichos espacios (Bochaca 2005). En el último cuarto del siglo XIX, con el desarrollo de la "ciudad nueva" o post terremoto, cristalizaría un modo de arbolado que ubicó los 
ejemplares junto a las acequias a ambos lados de las calles. Esta imagen será desde ese momento una de las más distintivas de los paisajes mendocinos. A partir de este período toman importancia también la forestación de plazas y parques, comenzando a ser la imagen del oasis arbolado una herramienta valiosa para las elites (Ponte 2006). Sin embargo, como veremos a continuación, la decisión de cuáles eran finalmente los árboles beneficiosos continuó siendo un tema de disputa.

Recapitulando, el paisaje forestal desarrollado a partir del periodo colonial, que era notablemente más familiar a las sensibilidades de los colonos, dio también lugar a espacialidades y temporalidades que estaban en resonancia con los nuevos modos productivos y con las actividades cotidianas de la sociedad colonial. Esto es evidente en las características materiales del paisaje forestal introducido. Del monte nativo constituido casi en su totalidad por plantas perennes, se pasó a uno conformado casi en su totalidad por plantas caducifolias. De este modo, los cambios dados en el cromatismo de sus hojas, así como por la floración y fructificación, resonaban con los cambios estacionales y acompañaban los ciclos del trabajo agrícola. A la vez, los árboles longevos como el olivo enlazaban ciclos más largos que podían unir a varias generaciones humanas. En cuanto a la relación con el clima, las plantas del monte nativo son casi todas de hojas pequeñas, de verdes grisáceos o azulados. En cambio, las plantas introducidas tienen hojas de tamaños mayores, de verdes más claros y amarillentos. Con este nuevo paisaje se reajustaron las experiencias en torno al clima, lo cual es evidente en algunas menciones documentales.

En este sentido, es interesante rescatar la discusión ambiental dada en los últimos años del siglo XIX, cuando se pusieron en disputa los sentidos "tradicionales" asociados a la experiencia colonial versus sentidos modernos impulsados por los gobiernos liberales. Los vecinos de la ciudad de Mendoza resistieron una serie de ordenanzas de gobierno que mandaban a erradicar, primero, o a reemplazar, después, el arbolado urbano de la ciudad formado en ese momento por especies introducidas (álamos carolinos). La medida fue propuesta por las elites modernistas, quienes argumentaban razones higiénicas para la eliminación de los árboles. Decían que serviría para sacar a la ciudad de su hacinamiento y permitir así la circulación del aire que barrería las bacterias. Se proponía plantar en torno a la ciudad arboledas de pinos $u$ otras plantas resinosas, argumentando que estas soltarían gases beneficiosos para la salud y cambiarían el clima. Especialmente, modificarían el régimen de precipitaciones, evitando las lluvias torrenciales y suprimiendo las bruscas variaciones de temperatura entre el día y la noche. Sin embargo, los vecinos de la ciudad, tenían sus propios argumentos y en base a su resistencia estas medidas nunca llegaron a realizarse. Ellos se proclamaron como mendocinos auténticos e identificaron la lucha por la conservación de los árboles con los valores tradicionales de la ciudad (Ponte 1999, pp. 205-235). En ese sentido, dicha resistencia era una continuidad de una sensibilidad más cercana a la colonial y expresaba el deseo auténtico de conservar sin cambios el entorno forestal habitado por los vecinos de la ciudad de fines del siglo XIX. Esto puede verse en las razones argumentadas en dicha resistencia, mencionándose la tradición, la belleza que le daban a la ciudad, la forma en la que homogeneizaba el paisaje y tapaban la pobre arquitectura. A la vez, se decía que estos árboles bajaban la temperatura en verano, lo cual era fundamental para la vida ya que "Mendoza es un enorme vientre de tierra" (Ponte 1999, p. 235). Vimos al comienzo de este trabajo cómo estas ideas están vigentes aún hoy, y el bosque de árboles introducidos en torno a las 
áreas habitadas en el norte de Mendoza se considera indispensable para que la vida humana sea posible.

Paradójicamente, mientras los vecinos de la ciudad de Mendoza oponían resistencia a la erradicación o reemplazo del arbolado urbano, eran indiferentes a las talas de los montes nativos realizadas en el mismo momento. Los bosques de algarrobo (Prosopis flexuosa) que se extendían a partir de los $25 \mathrm{~km}$ de la ciudad y cubrían grandes extensiones del noreste de la provincia de Mendoza se explotaron desde fines del siglo XIX al punto de agotarse solo algunas décadas después (Abraham y Prieto 1999, Rojas 2009, Rojas et al. 2009). En base a dicho impacto, no solo habrían desaparecido los bosques en condiciones industriales de explotación, sino que también los bosques climácicos de dicha especie (Roig 1972, p. 52).

\section{Epílogo}

A lo largo de este trabajo, analizamos información documental sobre las experiencias del ambiente en la provincia de Mendoza entre los siglos XVI a XIX, a partir de la cual discutimos la posible esquematización en la región de un tipo de relación entre la sociedad y su entorno. Partimos del ideario actual y buscamos sus raíces coloniales, nos detuvimos en testimonios relacionados a dos asociaciones específicas de materialidadessignificados o colectivos, que denominamos paisaje nativo y paisaje colonial. En este caso, a partir de las valoraciones presentes en distintos documentos históricos observamos el carácter de las experiencias, entendiéndolas como modeladas por la conformación de corporalidades en las que se estableció algún tipo de ajuste entre sensibilidades y materialidades-significados. Dicho proceso estaba dado en un desarrollo contextual, en especial relación con el lugar o paisaje en el que los actores llevaron adelante su vida. Reconocimos por ejemplo contrastes en la asociación de diferentes corporalidades con iguales materialidades, como en el caso de la cordillera o el monte nativo que se revelaba de manera disímil para indígenas y colonos.

Observamos cómo, en esta incorporación que predisponía las experiencias del ambiente, se incluían discursos o, más precisamente, proyecciones sobre lo que el ambiente podía ser. Estos se incorporaban como sentidos que configuraban de forma espontánea las relaciones con la materialidad. Concretamente, los colonos europeos se relacionaron con los lugares del Nuevo Mundo en base a una dicotomía que preveía, o bien una versión exageradamente benigna del ambiente, $\mathrm{u}$ otra exageradamente hostil; respectivamente, el "paraíso" y la "selvatiquez". Creímos reconocer las percepciones y experiencias tenidas en relación con los ambientes nativos de Chile y de Cuyo, como realizaciones de estas proyecciones. Así, observamos que los ambientes valorados positivamente no eran simplemente réplicas de los ambientes europeos como generalmente se propone, sino objetivaciones de lo que el ambiente podía ser en relación a corporalidades y prácticas concretas. Especialmente, subrayamos cómo los ambientes de Chile eran caracterizados por revelarse mayormente socializados, sin referir a unos totalmente domesticados en el sentido de transformados o cultivados, sino a otros en los que no podían distinguirse las tierras cultivadas de las incultas. En otros términos, lugares donde las prácticas y modos de vida europeos se hallaban en resonancia con las materialidades y los fenómenos ambientales. Por el contrario, la versión hostil del ambiente medieval o selvatiquez se materializaba en el ambiente nativo de Cuyo, donde el paisaje acopló los significados de los desiertos míticos de la biblia, abrasados por el sol, pedregosos y áridos, pero también 
"vírgenes". Ese ambiente, que podía corromper física o moralmente a las personas, también representaba un "vacío" desafiante; uno que hacía posible su redención. Dicho y hecho, estos terrenos hostiles comenzaron a transformarse en paradisíacos con la conformación de los paisajes introducidos. Así, Mendoza pasó a ser caracterizada por esta dicotomía, que puede resumirse en palabras de un visitante chileno del siglo XIX, como un lugar extraño donde era posible hallar "lo agreste y lo salvaje tan cercano a lo culto y civilizado" (Vicugna Mackena 1855 en Roig 2007, p. 578)

Planteamos que los árboles tuvieron un lugar especial en ese proceso, objetivando condiciones que facilitaron un cambio en la perspectiva, en paralelo al cambio en las materialidades. En este sentido, así como las referencias a los paisajes nativos son en general exageradamente negativas, especialmente los árboles nativos se consideraban o bien ofensivos o -al no ser reconocidos como tales- inexistentes. Por el contrario, cuando aparecen referencias a los paisajes introducidos o coloniales, y especialmente a los árboles, las valoraciones se vuelven exageradamente positivas. Estos valores presentes comúnmente en los discursos coloniales analizados pueden decodificarse como un conjunto de sentidos y prácticas entrando en resonancias temporales y espaciales con las materialidades de los paisajes coloniales en conformación.

De este modo, si bien la esquematización colonial de las relaciones con el ambiente posiblemente sentó las bases del ideario ambiental actual, el cual cristalizó a partir de la segunda mitad del siglo XIX, podemos señalar algunos matices. En primer lugar, en el caso colonial, no se trataba de una organización dicotómica de la realidad en base a una dualidad de naturaleza y cultura. Creemos que en ese momento las características especiales de un lugar se definían en base a qué tanto se ajustara el conjunto de fenómenos ambientales que lo caracterizaban a los sentidos y prácticas específicas de un grupo humano, sin importar que esto haya sido dado por la gracia de la creación divina o por la acción cultural. Así, el Chile paradisíaco era obra de la "naturaleza en su fábrica y disposición", mientras que en Mendoza fue el paisaje introducido el que dio lugar al paraíso, por lo que, aquí más que una dualidad silvestre/doméstico se generó una entre nativo e introducido. Esta dualidad resuena también en la dada entre los grupos humanos, resultando el paisaje introducido metáfora y prueba material de la preeminencia de la población blanca, de herencia migrante y colonial, por sobre los grupos nativos de herencia indígena. ${ }^{11}$

Si bien durante el siglo XIX se acoplaron las narrativas sobre el ambiente a los ideales de la Mendoza moderna cristalizando una historia regional que se relata como el avance de la cultura sobre la naturaleza, en base a lo argumentado en este trabajo podemos preguntarnos si parte de los sentidos que subyacen en estas narrativas son aún más antiguos. En ese sentido, los yermos desolados que aparecen en el cuadro de Cubillos o los mencionados en los trabajos históricos y en los relatos orales ¿son expresiones de la selvatiquez propia de la perspectiva colonial? De igual manera, ¿no heredan parte de estos sentidos otras interpretaciones científicas, especialmente aquellas que correlacionan degradación ambiental y empobrecimiento de las condiciones de existencia humana? ¿o se asemejan acaso los "desertícolas" en la "Antropología del Desierto" de L. Triviño a los hombres que perdieron el eje de la civilización en los relatos medievales? ${ }^{12}$ Así también, la experiencia actual en relación a los árboles en Mendoza ¿está mediada por una sensibilidad moderna, que prioriza lo funcional, racionaliza usos y optimiza variables de recursos?; o, por el contrario, ¿es parte de un modo de habitar donde plantas, mitos y corporalidades resuenan siguiendo una inercia que excede estos sentidos? Es por 
supuesto inoportuno abordar aquí estas preguntas, igualmente esperamos que este artículo haya sido útil para comprender la importancia de conformar un corpus de información que permita generarlas.

\section{BIBLIOGRAPHY}

Abraham, E. y Prieto, M. (1999). Vitivinicultura y desertificación en Mendoza. En B. García Martínez y A. González Jácome (Comps.), Estudios de historia y ambiente en América I: Argentina, Bolivia, México, Paraguay (pp. 109-135). México DF: El Colegio de México, IPGH.

Ambrosetti, J. (1972). Especies interesantes en la ordenación de la cuenca Papagallos I. Deserta, (2), 207-240.

Anónimo (2007, octubre 5). Mendoza se está quedando sin árboles. Diario Los Andes: Sección Editorial.

Arnold, D. (2000). La naturaleza como problema histórico: el medio, la cultura y la expansión de Europa. México: Fondo de Cultura Económica.

Bochaca, F. (2005). El verde en la estructura urbana de Mendoza. ARQ, (60), 68-71.

Bibar, G. (1952). Crónica y relación copiosa y verdadera de los Reynos de Chile. Santiago de Chile: Fondo Histórico Bibliográfico Juan Toribio Medina.

Boia, L. (2004). L'homme face au climat: l'imaginaire de la pluie et du beau temps. París: Les Belles lettres.

Brailovsky, A. E. (2009). Historia ecológica de Iberoamérica. Tomo 1: De los Mayas al Quijote. Buenos Aires: Editorial Kaicrón y Le Monde Diplomatique.

Canals Frau, S. (1945). Los huarpes y sus doctrinas. Un documento. Anales del Instituto de Etnología Americana, (3), 61-91.

Canals Frau, S. (1946). Etnología de los huarpes. Una Síntesis. Anales del Instituto de Etnología Americana (7), 9-148.

Castro, A. (2015). Plantas frutales. Cultura material en el reino de Chile. 1700 - 1850. Tesis de doctorado no publicada. Doctorado en Historia, Facultad de Filosofía y Letras, Universidad Nacional de Cuyo.

Chiavazza, H. (2010). Procesos sociales y ambientales en el sector urbano de Mendoza entre los siglos XV-XVIII: arqueología urbana e historia ambiental. Comechingonia Virtual, IV (2), 227-253.

Chiavazza, H. (2015). Pescadores, horticultores ceramistas del valle de Mendoza. En R. Bárcena (Ed.), Arqueología y etnohistoria, aportes desde las IV Jornadas Arqueológicas Cuyanas (pp. 45-65). CCTMendoza.

Chiavazza, H. y Mafferra, L. (2007). Estado de las investigaciones arqueobotánicas en Mendoza y sus implicancias en la arqueología histórica. Revista de Arqueología Histórica Argentina y Latinoamericana, (1), 127-152. 
Coria, L. (1988). Evolución económica de Mendoza en la época colonial. Mendoza: Facultad de Ciencias Económicas, Universidad nacional de Cuyo.

Darwin, C. (2003). Diario del viaje de un naturalista alrededor del mundo. Barcelona: Espasa Calpe.

Durán, V. y García, C. (1989). Ocupaciones agroalfareras en el sitio Agua de la Cueva Sector Norte (NO de Mendoza). Revista de Estudios Regionales (3), 29-64.

Escolar, D. (2007). Los dones étnicos de la Nación: Identidades huarpe y modos de producción de soberanía en Argentina. Buenos Aires: Prometeo Libros.

Escolar, D., Martín, F., Rojas, F., Saldi, L. y Wagner, L. (2012). Imaginario ambiental mendocino. Sus efectos en las políticas estatales y la producción científica. En A. Salomón y A. Zarrilli (Comps.), Historia, política y gestión ambiental: Perspectivas y debates (pp. 77-97). Buenos Aires: Imago Mundi.

Hell, B. (2001). Cazadores Rabiosos. El dominio del salvajismo en el noroeste de Europa. En P. Descola y G. Pálsson (Coord.), Naturaleza y sociedad: perspectivas antropológicas (pp. 237-252). México DF: Siglo XXI.

Gil, A. F., Neme, G. A., Tykot, R. H., Novellino, P., Cortegoso, V. y Durán, V. (2009). Stable isotopes and maize consumption in central western Argentina. International Journal of Osteoarchaeology, XIX (2), 215-236.

Herrera, Antonio de (1615). Historia general de los hechos de los castellanos en las islas y tierra firme del mar océano. Disponible en: <http://www.memoriachilena.cl/archivos2/pdfs/MC0012408.pdf >

Ingold, T. (2000). The Perception of the Environment. Londres: Rougledge.

Ingold, T. (2011). Being alive: Essays on movement, knowledge and description. Londres y Nueva York: Taylor \& Francis.

Jones, O. y Cloke, P. (2008). Non-human agencies: trees in place and time. En C. Knappett y L. Malafouris (Eds.), Material Agency (pp. 79-96). Nueva York: Springer \& Business Media.

García Sanchez, E. (2015). Las frutas de los califas. Producción y consumo de frutas en al-Andalus. En P. Lacoste, y J. Yuri (Comps.), Frutales, Cultura y Sociedad (pp. 83-107). Talca, Chile: Universidad de Talca.

Gonzáles de Nájera, A. (1889 [1601]). (Medina, T. Ed.). Desengaño y reparo de la guerra del Reino de Chile. Santiago de Chile: Imprenta Ercilla. Disponible en: <http://www.memoriachilena.cl/ archivos2/pdfs/MC0008853.pdf >

Lacoste, P., Yuri, J. A., Aranda, M., Castro, A., Quinteros, K., Solar, M. y Chávez, C. (2011). Variedades de Pomáceas (Chile y Cuyo 1700-1850). Idesia, XXIX (1), 91-97.

Latour, B. (1991). Nunca fuimos modernos: ensayo de antropología simétrica. Buenos Aires y México DF: Siglo veintiuno editores.

Mafferra, L. E. (2010). La problemática en torno al registro arqueobotánico en el norte de Mendoza. En R. Bárcena y H. Chiavazza (Comp.), Actas del XVII Congreso Nacional de Arqueología Argentina. Tomo V (pp. 2083-2088). Mendoza: Facultad de Filosofía y Letras, Universidad Nacional de Cuyo.

Mafferra, L. E. (2011). Interpretaciones del registro arqueobotánico en arqueología histórica. En M. Ramos, A. Tapia, F. Bognanni, M. Fernández, V. Helfer, C. Landa, M. Lanza, E. Montanari, E. Néspolo y V. Pineau, (Eds.), Temas y problemas de la Arqueología Histórica. Tomo 2 (pp. 43-52). Luján, Buenos Aires: Ed. PROARHEP-Universidad Nacional de Luján. 
Mafferra, L. E. (2015). Arqueología de los paisajes forestales del norte de Mendoza. Tesis de doctorado no publicada. Doctorado en Ciencias Antropológicas. Facultad de Filosofía y Humanidades, Universidad Nacional de Córdoba.

Mafferra, L. E. (2016a). Lo que ellas quieren. Actas del XIX Congreso Nacional de Arqueología Argentina . Serie Monográfica y Didáctica. Publicación de la Facultad de Ciencias Naturales, Instituto Miguel Lillo. UNT (54) pp.1533-1537. Disponible en: https://drive.google.com/file/ d/oBz1EVgxaeQyvQjhKSmNIaElnTkU/view

Mafferra, L. E. (2016b). Arqueobotánica del Norte de Mendoza. Interpretaciones sobre el rol de los vegetales en la interacción indígena-hispana durante los siglos XVI y XVII. Mendoza: Facultad de Filosofía y Letras de la Universidad Nacional de Cuyo, Serie de Publicaciones del CIRSF 10.

Mafferra, L. E. (2017). Los paisajes forestales en torno a la ciudad colonial de Mendoza, con base en el registro antracológico. Intersecciones en Antropología, XVIII (1), 43-53.

Maffera, L. E., Chiavazza, H. y Roig, F. (2015). El árbol que da frutos se corta y se echa al fuego. Discusiones sobre el uso de la leña en la Mendoza colonial. Comechingonia, XIX (2), 203-234.

Mellet, J. (1959 [1824]). Viajes por el interior de la América Meridional, 1808-1820. Santiago de Chile: Editorial del Pacífico.

Méndez, E. (1999). Bosques de Acacia furcatispina (Garabato) en cerrilladas pedemontanas de Mendoza. Deserta, (2), 157-161.

Michielli, C. (1983). Los huarpes protohistóricos. San Juan, Argentina: Instituto de Investigaciones Arqueológicas y Museo-UNSJ.

Montaña, E. (2007). Identidad regional y construcción del territorio en Mendoza (Argentina): memorias y olvidos estratégicos. Bulletin de l'Institut Français d'Études Andines, XXXVI (2), 277-297.

Nash, R. F. (2014). Wilderness and the American mind. New Haven, Connecticut: Yale University Press.

Ovalle, Alonso de (1646). Histórica Relación del Reino de Chile. Roma. Disponible en: <http:// www.memoriachilena.cl/archivos2/pdfs/mc0012104.pdf>

Paz, D. (2016, noviembre 6). La revolución mendocina se hace plantando árboles. Diario UNO: A Fondo.

Perosa, M., Rojas, F., Villagra, P., Tognelli, M., Carrara, R. y Alvarez, J. (2013). Distribución potencial de los bosques de Prosopis fexuosa en la Provincia Biogeográfica del Monte (Argentina). Ecología austral, XXIV (2), 238-248.

Ponte, J. R. (1999). La fragilidad de la memoria: representaciones, prensa y poder de una ciudad latinoamericana en tiempos del modernismo: Mendoza, 1885-1910. Mendoza: Ediunc.

Ponte, J. R. (2006). Historia del regadío. Las acequias de Mendoza, Argentina. Scripta Nova: Revista Electrónica de Geografía y Ciencias Sociales, X (218), 1-16.

Ponte, J. R. (2007). Mendoza, Argentina. El terremoto de 1861 como disparador del cambio de representación social de la identidad de una ciudad al pie de los Andes. Memoria y Sociedad, XI (23), 57-72.

Ponte, J. R. (2015). La cartografía hidráulica en Mendoza, Argentina (siglos XVIII y XIX) como herramienta para historiar el espacio y espacializar la historia. Agua y Territorio, (5), 26-37.

Prieto, M. R. (1985). Relaciones entre clima, condiciones ambientales y asentamientos humanos en la provincia de Mendoza en los siglos XVI, XVII, y XVIII. Revista de Historia Americana IPGH, (100), 79-118. 
Prieto, M. R. (1987). La mentalidad mendocina durante la Colonia. La cordillera como factor condicionante. Serie científica, (32), 18-21.

Prieto, M. R. (1989). Historia de la ocupación del espacio y el uso de los recursos naturales en el Piedemonte de Mendoza. En F. Roig (Ed.), Detección y control de la desertificación (pp. 139-153). Mendoza: CONICET, CRICYT, IADIZA.

Prieto, M. R. (2000). Formación y consolidación de una sociedad en un área marginal del Reino de Chile: La Provincia de Cuyo en el siglo XVII. Anales del Instituto de Arqueología y Etnología, (52-53), 18-366.

Prieto, M. R. (2007). Variaciones y anomalías climáticas y su impacto socioeconómico en Mendoza en los últimos 500 años. En: A. Roig y M. C. Satlari (Comps.), Mendoza, identidad, educación y ciencias (pp. 605-653). Mendoza: Ediciones Culturales de Mendoza.

Prieto, M. R. y Chiavazza, H. (2006). Aportes de la historia ambiental y la arqueología para el análisis del patrón de asentamiento Huarpe en el oasis norte de Mendoza. Anales de Arqueología y Etnología, (59-60), 159-190.

Prieto, M. R., Villagra, P. E., Lana, N. B. y Abraham, E. (2003). Utilización de documentos históricos en la reconstrucción de la vegetación de la Llanura de la Travesía (Argentina) a principios del siglo XIX. Revista Chilena de Historia Natural, LXXVI (4), 613-622.

Prieto M. R. y Wuilloud, C. F. (1986). Consecuencias ambientales derivadas de la instalación de los españoles en Mendoza en 1561. Cuadernos de historia regional, Universidad Nacional de Luján, II (6), 3-35.

Roig, F. (1972). Bosquejo fisonómico de la vegetación de la provincia de Mendoza. Boletín de la Sociedad Argentina de Botánica, XIII, 49-80.

Roig, F. A., Martínez Carretero E. y Méndez, E. (2000). Vegetación de la provincia de Mendoza. En E. M. Abraham, y F. Rodríguez Martínez (eds.), Recursos y problemas ambientales de la zona árida. Primera parte: provincias de Mendoza, San Juan y La Rioja. Tomo I: Caracterización ambiental (pp. 63-64). Mendoza: IADIZA-Universidad de Granada.

Roig, V. (2007). Datos sobre el conocimiento y las investigaciones zoológicas. En A. Roig y M. C. Satlari (Comps.), Mendoza, identidad, educación y ciencias (pp. 559-604). Mendoza: Ediciones culturales de Mendoza.

Rojas, F. (2009). Deforestación en Mendoza y San Juan entre 1900 y 1942. Distribución espacial y procesos socioeconómicos sobre el desmonte de los algarrobales. Tesis de licenciatura no publicada. Licenciatura en Geografía. Facultad de Filosofía y Letras, Universidad Nacional de Cuyo.

Rojas, F., Prieto, M. R., Álvarez, J. y Cesca, E. (2009). Procesos socioeconómicos y territoriales en el uso de los recursos forestales en Mendoza desde fines de siglo XIX hasta mediados del XX. Revista Proyección, II (7), 1-33.

Saldi, L. (2010). Construcciones metonímicas opuestas de espacio - identidad - economía y sus entre-medios en el Noreste de Mendoza. Kula, (2), 9-23.

Saldi, L., Wagner, L. y Escolar, D. (2014). Social discourses on environmental themes: water and mining in central west Argentina. Ambiente \& Sociedade, XVII (1), 97-114.

Saldi, L. (En prensa). Reflexiones sobre los mitos provinciales de la subalternidad. El desierto, la pobreza y huarpidad apolítica en cuestión. San Juan, Argentina: Publicaciones del Colectivo de Arqueología Cuyana. 
Segheso de López Aragón, C. (2004). El proceso constituyente mendocino. En A. Roig, P. Lacoste y M.C. Satlari (Comps.), Mendoza cultura y economía (pp. 225-255). Mendoza: Caviar Bleu.

Vigil, J. M. S. (2003). Bases de partida para estudios sobre los montes españoles en la Edad Media: publicaciones de referencia, fuentes de datos y conclusiones. Cuadernos de la Sociedad Española de Ciencias Forestales, (16), 79-83.

\section{NOTES}

1. Una versión preliminar de este trabajo fue presentada como ponencia en el Congreso Nacional de Arqueología Histórica Argentina, realizado en Mendoza en el año 2015. El título de este trabajo fue compuesto con base en un testimonio del siglo XVII referido a nuestra zona de estudio "...fin que fe vea (...) vn arbol, que de alegria, ni vna amenidad que recree" (Ovalle 1646: 29 -sic-).

2. Por ejemplo Herrera 1615; González Nájera [1601] 1889; Bibar 1952; Mariño de Lobera 1584 en Prieto 2000.

3. Por ejemplo Ovalle 1646; Techo 1897 en Michieli 1983; Miguel de Olivares 1736, 1778 ambos en Prieto 2000; Gómez de Vidaurre 1776 en Prieto 2000, Anónimo [1787] 1940 en Prieto 2000.

4. Lizarraga s.f. en Canals Frau 1946.

5. Anónimo en Canals Frau 1945, Cartas Anuas 1927 en Prieto 2000.

6. Mellet [1824]1959; Darwin 2003.

7. Proceso a Villagra en Prieto y Wuilloud 1986.

8. Subrayamos aquí cómo los indígenas son animalizados en el relato, lo que analizaremos más adelante.

9. Esto sacaría de plano, además, la propuesta de autores que argumentan que los testimonios negativos sobre los paisajes nativos de la América recién descubierta, eran parte de un discurso general que justificaba y encubría el saqueo y el genocidio (Brailovsky 2009, p. 109-111).

10. Esta toma de distancia con la "naturaleza" constituye además, como lo señala B. Latour (1991), un ejercicio de purificación que permite la distinción entre objeto y sujeto cognoscente, división sin la cual no hay posibilidad de modernidad ni, consecuentemente, de ciencia.

11. Montaña (2007, p. 285-287) identifica al "labriego tesonero" y a los "domadores del agua", ambos trabajadores abnegados de raíz migrante, como personajes claves en los mitos identitarios regionales donde el desierto se transforma en un vergel. Así también, Saldi (2010, p. 16) realiza un estudio interesante sobre la justificación que se esgrime para la exclusión de las poblaciones indígenas del oasis, por "tranquilos" o "vagos".

12. Un análisis más profundo de los Paradigmas de la Desertificación y la Antropología del Desierto, en relación con el ideario ambiental regional puede consultarse en Escolar (et al. 2012) y Saldi (en prensa).

\section{ABSTRACTS}

Starting off from the current environmental conceptions in the Mendoza province (Argentina), we analyze here documentary information about its historical roots. More precisely, we observe testimonies about the experience of the environment between the sixteenth and nineteenth centuries, detecting clues allowing context understanding of the schematization of modalities in 
the relationship between society and its environment. We are particularly interested in observing the place of the plants in this process; since from archaeological and historical data it has been corroborated that the period of study covered changes in the conformation of the forest landscapes. For this purpose, we broadly define units of analysis differentiated by the association of materialities-meanings that conformed specific landscapes, more precisely, the native and colonial landscape. The analyzed data allows for observation of different relationship between both; resulting trees and shrubs possible key elements in the modeling of experiences. These interpretations make it possible to resume the debate that was used as a starting point, discussing, on the basis of the historical information presented and the interpretations built throughout the paper, the implications of current conceptualizations and modes of relation with the environment in the region.

A partir de las concepciones actuales sobre el ambiente en la provincia de Mendoza (Argentina), analizamos en este trabajo información documental sobre sus raíces históricas. Más precisamente, observamos testimonios sobre la experiencia del ambiente entre los siglos XVI y XIX, detectando indicios que permiten comprenderla en el contexto de la esquematización de modalidades de relación entre la sociedad y su entorno. Nos interesa especialmente observar el lugar de las plantas en este proceso; ya que en base a datos arqueológicos e históricos se ha corroborado que el período de estudio incluyó cambios en la conformación de los paisajes forestales. Asimismo, definimos a grandes rasgos unidades de análisis diferenciadas por la asociación de materialidades-significados que conformaron paisajes específicos, más precisamente, el paisaje nativo y el colonial. Los datos analizados permiten observar disposiciones de relación diferentes entre ambas; resultando los árboles y arbustos posibles elementos claves en la modelación de las experiencias. Estas interpretaciones habilitan para retomar el debate que sirvió de punto de partida discutiendo, a razón de la información histórica presentada y las interpretaciones construidas a lo largo del trabajo, las implicancias de las actuales conceptualizaciones y modos de relación con el ambiente en la región.

\section{INDEX}

Keywords: Experiences, relationships, environment, native landscapes, colonial landscapes, trees

Palabras claves: Experiencias, relaciones, ambiente, paisajes nativos, paisajes coloniales, árboles

\section{AUTHORS}

\section{LUIS E. MAFFERRA}

Instituto Argentino de Nivología, Glaciología y Ciencias Ambientales, Centro Científico

Tecnológico-Mendoza; Instituto de Etnología y Arqueología Salvador Canals Frau, Facultad de

Filosofía y Letras, Universidad Nacional de Cuyo; Argentina

Correo electrónico: luismafferra@gmail.com

\section{BERNARDA MARCONETTO}

Instituto de Antropología de Córdoba, CONICET, Universidad Nacional de Córdoba, Argentina

Correo electrónico: Bernarda.marconetto@gmail.com 